\title{
La noción de prejuicio en la obra de Immanuel Kant
}

\section{Notion of Prejudice in the Works \\ of Immanuel Kant}

\author{
Pedro Jesús TERUEL \\ Universidad de Valencia
}

Recibido: 22/01/2013

Aceptado: 12/08/2013

\section{Resumen}

La noción de prejuicio ocupa un lugar no del todo visible en la producción kantiana. De hecho, ha sido escasamente tematizada en los estudios kantianos en lengua alemana, inglesa, francesa, italiana o española. Sin embargo, entronca con algunos de los hilos conductores básicos tanto de la Crítica de la razón pura $\left(1781^{1}, 1787^{2}\right)$ como de la Crítica de la razón práctica (1788) y la Crítica del juicio (1790). El objeto del texto consiste en abordar la noción kantiana de prejuicio, su ubicación sistemática y sus fuentes (entre éstas, particularmente la obra de Georg Friedrich Meier y el pensamiento de Christian Thomasius).

Palabras clave: Ilustración, Immanuel Kant, Juicio, Prejuicio.

\begin{abstract}
The notion of prejudice occupies a not very visible place in the Kantian works. In fact it has been seldom treated in Kantian studies in German, English, French, Italian or Spanish. But it connects with relevant key notes of the Critique of Pure Reason $\left(1781^{1}, 1787^{2}\right)$ as well as from the Critique of Practical Reason (1788) and the Critique of Judgement (1790). The aim of this paper consists in the analysis of the Kantian notion of prejudice, its systematic place and its sources (among these particularly the works of Georg Friedrich Meier and the thought of Christian Thomasius).
\end{abstract}


Keywords: Enlightenment, Immanuel Kant, Judgement, Prejudice.

Del latín praeiudicium -ii, 'juicio previo' o 'decisión prematura', el castellano 'prejuicio' aparece testimoniado literariamente en $1884 \mathrm{y}$, en cierto sentido, ya en el siglo $\mathrm{XV} .{ }^{1}$ La etimología de 'prejuicio' sugiere que se trata del momento previo a la emisión de un juicio. Habrá que preguntarse, pues, qué es un iudicium. El diccionario latino señala que se trata de un proceso ante tribunal, en el que se dirime una causa civil o criminal, y también de la sentencia o decisión ligada a ese proceso; por extensión, con el término se alude al acto y al producto de la acción de discernir, de reflexionar, de opinar.

Si un prejuicio es un juicio previo, ¿en qué consistirá? ¿Quizá en un juicio cuyo resultado está decidido de antemano? ¿Hablaremos de prejuicio sólo cuando una toma de posición previa se demuestra equivocada, o también cuando acierta? ¿Nos referiremos quizá a la actitud (o a la fase) previa al acto judicativo? En este último caso, nos encontraríamos siempre sumidos en un estado de prejuicio, del que únicamente saldríamos para pronunciarnos de manera explícita sobre algún asunto.

El prejuicio parece ocupar un espacio difuso entre la concreción pública de una toma de postura (ante el tribunal de la ley o de la propia conciencia) y las condiciones cognitiva o cronológicamente previas a ella. Podemos señalar, al menos, dos cuestiones inicialmente ambiguas: en primer lugar, la posibilidad de calificar como prejuicio tanto una postura errada como una correcta; en segundo lugar, el significado mismo de la noción de postura judicativa previa.

El objeto de esta contribución consiste en abordar la noción de prejuicio en la obra de Immanuel Kant. ${ }^{2}$ Tomaré en consideración una hipótesis fuerte, a saber: que el hilo conductor de la obra de Immanuel Kant reside, precisamente, en la eliminación de los prejuicios. Poderosas razones nos llevan a inclinarnos, de entrada, a favor de esta hipótesis: no en vano la Ilustración -movimiento cultural cuyo trasunto se halla en el ensayo kantiano de 1784 Respuesta a la pregunta: ¿Qué es Ilustración?- llevaba en sus entrañas la causa de la emancipación de la razón autónoma de las instancias externas que la llevan a juzgar mal, o a prejuzgar, lo real, y se desarrolló en un marco sociocultural marcado por el abigarrado despliegue de polémicas políticas, morales y religiosas en las que la identificación y remoción del prejuicio estaba llamada a ocupar un lugar central. He aquí, pues, el Leitmotiv de las páginas que siguen, en las que se afronta una cuestión escasamente tematizada en las principales lenguas que vehiculan los estudios kantianos. ${ }^{3}$

${ }^{1}$ Cfr. Coromines, J., Breve diccionario etimológico de la lengua castellana (1961), p. 324.

${ }^{2}$ Agradezco de corazón a los evaluadores del artículo las sugerencias que me han hecho llegar y que sin duda han contribuido a mejorar el texto.

${ }^{3}$ Los análisis sistemáticos sobre la comprensión kantiana del prejuicio son escasos tanto en lengua alemana como inglesa, francesa, italiana y española. Rudolf Eisler recogió una breve 


\section{Aproximación preliminar desde la noción de juicio}

Es bien conocida la distinción bipartita que vertebra la Crítica de la razón pura. ${ }^{4}$ El conocimiento objetivo viene aquí concebido como trabajo de síntesis entre la multiplicidad empírica de la intuición y las formas a priori de la sensibilidad, por un lado, y como síntesis entre el fenómeno así obtenido y las categorías que permiten aprehenderlo intelectualmente, por otro. La tarea de la facultad sensible (Anschauung) consiste en suministrar los elementos de la intuición (tanto las formas puras a priori como las afecciones a posteriori). Por su parte, el entendimiento (Verstand) proporciona las estructuras que permiten apropiarnos intelectualmente la realidad, aferrarla (begreifen) por medio de conceptos (Begriffe). Éstos no constituyen elementos aislados o inconexos, sino que intervienen en la formación de tomas de postura -de juicios- por medio de los cuales ante el tribunal trascendental de la conciencia (Bewußtsein) se decide -se juzga- qué representación de los objetivos estados de cosas concuerda con las condiciones subjetivas de validez del conocimiento. A tal efecto, el entendimiento produce no sólo conceptos, sino también principios. Dichos principios regulan el uso adecuado de la facultad de juzgar, que por este motivo viene caracterizada como aquélla que se ocupa de subsumir los casos concretos bajo reglas generales (conceptuales). ${ }^{5}$

Así pues, la facultad trascendental del juicio ocupa un lugar transversal en la articulación de la Crítica de la razón pura. En efecto, la acción y el efecto de subsumir no

caracterización, bajo la voz 'Vorurteil', en su Kant-Lexikon. La voz 'Prejudice' se halla también incluida en la publicación electrónica $A$ Kant Dictionary, coordinada por Howard Caygill. Katerina Deligiorgi ha aludido a este asunto en las páginas 80-82 de su monografía Kant and the Culture of Enlightenment. En italiano, Paula Rumore se ha ocupado del tema en su introducción a la traducción de la obra Beyträge zu der Lehre von den Vorurtheilen des menschlichen Geschlechts de Georg Friedrich Meier: Contributi alla dottrina dei pregiudizi del genere umano, pp. I-XL. A este respecto se puede consultar la reseña de Salvatore Stefanelli aparecida en Recensioni filosofiche (en línea: http://www.recensionifilosofiche.it).

${ }^{4}$ A lo largo de este texto me referiré a las obras de Immanuel Kant según la edición canónica de la Real Academia prusiana de Ciencias (Ak), indicando volumen y número de página. Me he servido de dicho texto tal y como éste aparece en la edición digital de las obras completas llevada a cabo por Karsten Worm: Kant im Kontext II. Komplettausgabe (Berlín, InfoSoftWare, 2003). En el caso de la Kritik der reinen Vernunft seguiré el procedimiento usual de citación, indicando con las siglas A y B, seguidas del número de página, la primera y la segunda edición (1781 y 1787, respectivamente). A menos que se indique lo contrario, todas las traducciones - tanto de fuentes originales como de literatura secundaria- son mías.

${ }^{5}$ «Si definimos el entendimiento en general como la facultad de las reglas, el juicio es la facultad de subsumir bajo reglas, es decir, de discernir si algo se halla bajo una regla dada (casus datae legis) o no» (B 171). 
atañe sólo a la relación de unos conceptos con otros (por ejemplo, en el contexto lógico de teorías científicas), sino también a la adscripción de una representación sensible a un concepto u otro. Esta idea se hallaba presente ya en época precrítica, cuando Kant apuntaba a esta capacidad de discriminar -de juzgar- como el fundamento último de la diferencia entre seres humanos y animales en general. ${ }^{6}$

La facultad de juzgar posee principios universales, inscritos en la estructura apriórica del entendimiento. El primero de ellos es el principio supremo de todos los juicios analíticos, a saber, el de no contradicción; el segundo corresponde a los juicios sintéticos: la necesidad de que se den las condiciones para la unidad sintética de la multiplicidad empírica en una experiencia posible y, muy particularmente, la apercepción originaria. De manera subordinada a estas condiciones, la primera Crítica desgrana el sistema de los principios del entendimiento puro: axiomas de la intuición, anticipaciones de la percepción, analogías de la experiencia y postulados del pensar empírico en general. ${ }^{7}$

Hay que notar que la facultad de juzgar posee una dimensión subjetivo-empírica. Pese a su estructural objetividad y a su validez universal, su despliegue biográfico en el individuo concreto se halla sujeto a mediaciones de índole social y cultural. A la luz de esto último se comprende que la facultad de juzgar haya de ser promovida, ayudada, educada desde los ámbitos donde dichas mediaciones tienen lugar; es en este contexto en el que Kant subraya la relevancia de los ejemplos, auténticos "andadores" del juicio. ${ }^{8}$ Por otro lado, el oscurecimiento patológico del juicio da lugar a una forma particular de perturbación mental. El autor trata este asunto en un breve escrito de 1764, el Ensayo sobre las enfermedades de la cabeza. Por causas patológicas -que Kant no atribuye en primera instancia a desajustes cerebrales- una persona puede forjarse conceptos adecuados sobre la base de intuiciones fidedignas y, no obstante, colocarlos bajo conceptos generales errados, debido a un uso impropio de los principios judicativos (sean éstos particulares o trascendentales). Es el caso, entre otros, de la persona que sufre algún tipo de delirio (Wahnsinn): aquélla que lo padece

ve o se acuerda de los objetos tan correctamente como cualquier individuo sano, sólo que por lo general interpreta la conducta de otras personas desde sí mismo, a través de un delirio absurdo, y cree por ello poder leer quién sabe qué preocupantes intenciones, que a ella no se le pasan jamás por la cabeza. Al escucharle se habría de creer que la ciudad entera está pendiente de él. La gente del mercado, que comercia entre sí y que repara en él de pasada, urde ataques en perjuicio suyo; el vigilante nocturno

${ }^{6}$ Cfr. Die falsche Spitzfindigkeit der vier syllogistischen Figuren erwiesen von I. Kant (1762), Ak II 59-60.

${ }^{7}$ Cfr. B 189/A 150-B 274/A225.

${ }^{8}$ Cfr. B 173-174. 
lo llama para tomarle el pelo; en definitiva, no ve otra cosa que una general conjura en su contra. ${ }^{9}$

De las observaciones kantianas sobre los principios que han de regir la actividad judicativa se deduce que una teoría basada sobre silogismos aparentes, una afirmación construida sobre la carencia de datos suficientes que la sustenten o la denuncia de una general trama conspiratoria en torno a sí no constituyen prejuicios, sino casos de errores judicativos (desde el punto de vista trascendental, empírico o patológico).

Pues bien: estamos ya en condiciones, sobre la base de lo dicho, de afrontar directamente el tema que nos ocupa. Me acabo de referir a la (errada) actualización de la facultad de juzgar en tres ámbitos de sentido: trascendental, empírico y patológico. El primero de ellos no admite actitud prejudicativa alguna: las estructuras trascendentales del conocimiento objetivo no pueden ser precedidas por otras cualesquiera (en otras palabras: para seres racionalmente constituidos no existirían, según Kant, estructuras trascendentales alternativas); así, por ejemplo, el paralogismo no procede de la aplicación de (hipotéticos) principios trascendentales falsos, sino de la subrepción de elementos heterogéneos en un silogismo cuya validez es, por ello, sólo aparente (es el caso de los paralogismos de la razón pura tratados en la Dialéctica de la primera Crítica). ${ }^{10}$ Por su parte, el tercero de los ámbitos citados (el patológico) requiere de consideraciones empíricas previas que exceden la esfera epistemológica general para enmarcarse en el contexto de la psicología experimental del caso concreto. ${ }^{11}$ El único marco en el que puede darse el prejuicio en sentido propio es el del conocimiento objetivo en la esfera de la experiencia.

Se podría afirmar, partiendo de esto, la existencia de un prejuicio positivo y de uno negativo. Un prejuicio positivo sería aquella operación intelectual que sienta las bases que permiten el desarrollo de un juicio en concordancia con las condiciones trascendentales y empíricas del conocimiento objetivo; en cambio, un prejuicio negativo corrompería en su raíz dicha acción judicativa adecuada. Sin embargo, esta hipotética distinción entre un sentido positivo y uno negativo de la noción de prejuicio no halla fundamento en la obra de Kant. Para el regiomontano, todo prejuicio se encuentra esencialmente gravado por una nota peyorativa. En breve estaremos en condiciones de explicar el porqué.

\footnotetext{
${ }^{9}$ Untersuchung über die Krankheiten des Kopfes (1764), Ak II 268. Este divertido pasaje apunta al origen de teorías conspiratorias de toda laya, de las que tenemos noticia filosófica desde que Anito, Meleto y Licón acusaran a Sócrates.

${ }^{10}$ Cfr. Teruel, P. J.: “Das „Ich denke“ als ,,der alleinige Text der rationalen Psychologie”, pp. 215-241.

${ }^{11}$ Cfr. Teruel, P. J.: "Die äußere Schaale der Natur. Eine Fußnote zum Versuch über die Krankheiten des Kopfes (1764)", pp. 23-43.
} 


\section{Articulación de la noción kantiana de prejuicio}

A mi modo de ver, la noción kantiana de prejuicio posee tres grandes acepciones, estrechamente emparentadas entre sí y todas ellas peyorativas: la epistemológica general, la epistemológica particular o científico-natural y la práctica. La primera aparece explícitamente en la letra kantiana; por su parte, el lugar conceptual de la segunda y de la tercera puede ser deducido sin forzar los textos. Veámoslo.

\subsection{Primer sentido: epistemológico general}

Esta acepción aparece en el ámbito general del uso del intelecto. Podemos conjeturar, en buena lógica, que este primer sentido habrá de apuntar a aquellas disposiciones intelectuales que provocan una incorrecta actualización de la capacidad de juzgar. Esto podrá suceder en dos direcciones: suscitando la tosquedad teorética que permite la construcción y validación de silogismos sólo aparentes o bien promoviendo la desatención intelectual que da por buenos juicios con insuficiente fundamento. En ambos casos se tratará de un intelecto descuidado respecto de su propio uso e irresponsable en relación con sus productos: un intelecto perezoso y desatento - inmaduro, podríamos decir.

Esta hipótesis queda corroborada por el texto de lógica publicado en 1800 a partir de las lecciones de Kant:

Los prejuicios son juicios provisionales, en tanto en cuanto éstos son aceptados como principios. Cada prejuicio ha de ser visto como principio de juicios errados; de los prejuicios no brotan prejuicios, sino juicios equivocados. Se debe distinguir por ello el conocimiento falso (que brota del prejuicio) de su fuente (del prejuicio mismo). Así, por ejemplo, el significado atribuido a los sueños no es en sí prejuicio alguno, sino un error, que brota de la aceptación de una regla general, a saber: lo que se cumple alguna vez, se cumple siempre o ha de ser tenido siempre por verdadero. Y este principio, bajo el cual se coloca la interpretación de los sueños, es un prejuicio. En ocasiones, los prejuicios son juicios provisionales verdaderos; que rijan para nosotros como principios o como juicios determinantes, esto es ya erróneo. La causa de esta confusión ha de ser buscada en el hecho de que tomamos equivocadamente por objetivos fundamentos que son subjetivos; y esto, por falta de la reflexión que debe preceder a todo juicio. ${ }^{12}$

La primera parte de este pasaje confirma nuestra afirmación de que un prejuicio ha de distinguirse de un juicio erróneo. Su última frase caracteriza el prejuicio en térmi-

${ }^{12} \operatorname{Logik}$ (1800), Ak IX 75-76 (el subrayado es mío). Cfr. en este sentido la Reflexion zur Logik n. 2529. 
nos típicamente kantianos: se trata de la confusión entre los fundamentos objetivos y subjetivos del juicio, de manera que su producto es un acto judicativo sólo aparentemente correcto.

Notemos que Kant apunta a la causa del prejuicio en un modo que lo pone en relación directa con la primera Crítica. Antes he señalado cómo el prejuicio se origina por tosquedad en la articulación lógica del pensamiento o por desatención intelectual a sus fundamentos empíricos; en ambos casos se produce una confusión entre la pretendida objetividad de las propias tesis y unos fundamentos de juicio que son meramente subjetivos, de modo que se hace pasar por objetivo algo que no lo es.

Comparemos esta explicación con el modo en que Kant describe el origen del espejismo trascendental (transzendentaler Schein) que da lugar a los paralogismos de la razón pura. Después de señalar cómo a partir de la unicidad, simplicidad, substancialidad y necesidad de la síntesis de la multiplicidad empírica en la apercepción trascendental se colige (erróneamente) los atributos del alma propios de la metafísica tradicional, Kant recapitula como sigue:

Así pues, por medio del análisis de la conciencia de mí mismo en el pensamiento en general no se ha ganado lo más mínimo por lo que respecta al conocimiento de mí mismo como objeto. La exposición lógica del pensamiento en general es tomada falsamente por una determinación metafísica del objeto. ${ }^{13}$

Esta conexión desvela algo relevante en la arquitectura de la primera Crítica. El origen del espejismo trascendental ha de ser buscado fuera de la razón pura - no en la sensibilidad, puesto que ésta no juzga, sino en la intromisión de elementos subjetivos en el juicio. La dialéctica trascendental (que ocupa la sección más amplia de la primera Crítica) está vertebrada por la pesquisa policial en torno a un prejuicio, a su origen y al modo de desenmascararlo.

Así pues, el prejuicio queda caracterizado como la confusión entre los fundamentos objetivos y subjetivos del juicio. Desde el punto de vista de su vertiente empírica se halla conectado con la configuración de las tomas de postura en un determinado contexto cultural, espaciotemporalmente localizado; se trata de un asunto que excede el marco de los intereses kantianos, aunque el propio Kant expresa (a su pesar) jugosos prejuicios sobre el carácter de distintos pueblos en sus lecciones sobre antropología. En cambio, la vertiente trascendental del prejuicio - en la medida en que éste oscurece las condiciones de posibilidad del conocimiento objetivo- ocupa un papel nuclear en el proyecto crítico. Tal cercanía del concepto general de prejuicio al origen de los errores metafísicos se halla testimoniada en anotaciones realizadas desde los

${ }^{13}$ B 409 . 
años de redacción de la Crítica de la razón pura hasta la década de los noventa. ${ }^{14} \mathrm{La}$ primera Crítica contiene, en este sentido, una educación contra el prejuicio. Eso sí, su pedagogía no es explícita sino implícita: no analiza en detalle las causas del prejuicio, sino que muestra cuáles son las condiciones que posibilitan el juicio objetivo.

Dado que se trata de condiciones previas a las tomas de postura, y no de meros juicios errados, los prejuicios se resisten a los intentos de modificación o eliminación. Kant es consciente de esto ya desde los inicios de su obra. Las personas con prejuicios «no admiten la instrucción», ya que «la juzgan por medio del mismo prejuicio que habría de ser removido». Por este motivo, los prejuicios «son más perjudiciales que la ignorancia». ${ }^{15}$

\subsection{Segundo sentido: epistemológico científico}

La segunda acepción tiene que ver con una cierta aproximación (errónea) al estudio de la Naturaleza. Su causa última reside en la acedia. La razón perezosa se resiste a indagar en la estructura y dinámica de la realidad natural con arreglo a leyes racionales unitarias. Dicho de otra manera: rechaza el esfuerzo necesario para articular una visión de la Naturaleza en la que todas sus partes se hallen interrelacionadas con arreglo a principios finalísticos - una visión, pues, teleológica.

Uno de los grandes rendimientos de la Crítica del juicio consiste, precisamente, en el refinamiento epistemológico de la noción de teleología, tratada ya con detenimiento en la sección sobre el uso regulativo de las ideas de la razón incluida como apéndice a la Dialéctica trascendental de la primera Crítica. La Naturaleza se despliega ante los ojos del observador como un horizonte de estructuras físicas y biológicas fascinante y potencialmente infinito. El interés sistemático de la razón origina máximas trascendentales subjetivas, que permiten considerar la multiplicidad bajo el punto de vista de la afinidad y de la unidad.

En la tercera Crítica, el uso regulativo de las ideas de la razón pura se extiende a la consideración de la Naturaleza como escenario de una lógica finalística que culmina en el ser humano como fin en sí mismo. De esta manera, como es sabido, se conecta la esfera teorética (relativa a la constitución de la Naturaleza) con la esfera práctica (pro-

\footnotetext{
${ }^{14}$ Así, por ejemplo, «el prejuicio es la propensión del entendimiento a juzgar desde causas subjetivas», Reflexion zur Logik n. 2534 (puesto que Adickes la data en la fase $v, \chi$ o $\theta$, hay que situar su redacción entre los años 1776-78, 1778-79 ó 1780-83). Cfr., en el mismo sentido, Reflexionen zur Logik n. 2539, 2545, 2550 (ya durante la década de los noventa). En la Reflexion n. 2550 pone en relación explícita la noción de prejuicio con la de espejismo o ilusión (Schein) trascendental.

${ }^{15}$ Reflexion zur Logik n. 2516 (fase $\beta 1,1752-1755$ ).
} 
pia de las acciones en el marco de la libertad). Este principio teleológico constituye una herramienta hermenéutica básica. Se trata de una perspectiva que el sujeto necesariamente adopta en la consideración de la Naturaleza: ésta ha de ser contemplada como si fuese el escenario de una teleología objetiva sólo sobre cuya base resulta posible la más unitaria síntesis de la multiplicidad empírica. El investigador plantea preguntas a la Naturaleza sobre la base de su comprensión teleológica y la Naturaleza le responde devolviéndole la imagen de un todo en dinamismo unitario. La interpretación als $o b$ se convierte así en una poderosa herramienta heurística, en la que lectores de Kant como Hans Vaihinger avistaron el núcleo intelectualmente más provechoso del pensamiento crítico.

Estamos ya en condiciones de entender la modulación epistemológico-científica del prejuicio. Obviar el dinamismo unitario de la comprensión teleológica de la Naturaleza para recurrir directamente a causas metafísicas constituye, afirma Kant, el error de una razón perezosa (ignava ratio, faule Vernunft) ${ }^{16}$; ésta renuncia a su autonomía, abandona la serie unitaria de causas físicas y realiza un salto ilícito al ámbito suprasensible. Fácilmente se desliza hacia la superstición, que no es una forma de fe sino un sucedáneo de ésta (Aberglaube).

Kant no pretende eliminar la comprensión metafísica de la experiencia, que a su modo de ver se muestra como irrenunciable desde la perspectiva de la razón práctica. El sentido de su crítica apunta a las pretendidas explicaciones de lo real que hacen caso omiso de la legalidad propia de la Naturaleza para saltar desde la indagación física a la explicación metafísica, ignorando la diferencia de nivel epistemológico. En este sentido el prejuicio consiste, pues, en no reconocer la ordenación y teleología internas de la Naturaleza. Entraña el desprecio hacia una realidad prejuzgada como no ordenada según una propia legalidad específica. Esto, a su vez, implica cerrar la puerta a la inteligibilidad científica del mundo. La prevención de esta dinámica perversa constituye, pues, un hilo conductor de la Crítica del juicio.

\subsection{Tercer sentido: práctico}

Existe aún una tercera vía bajo la que comparece el prejuicio: se trata de la subrepción en la moralidad de un principio subjetivo como si fuera objetivo. Dicha subrepción trae consigo la determinación de la voluntad por móviles ajenos a su propia legislación autónoma. Tal heteronomía fue considerada por Kant en la Fundamentación de la metafísica de las costumbres (1785) como la "fuente de todos los principios inauténticos de la moralidad". ${ }^{17} \mathrm{Su}$ comparecencia en la historia de las

\footnotetext{
${ }^{16} \mathrm{Cfr}$. B 717/A 689, B 801/A 773.

${ }^{17}$ Grundlegung zur Metaphysik der Sitten (1785), Ak IV, 441.
} 
ideas fue objeto de amplias reflexiones recogidas sustantivamente tres años después en la Crítica de la razón práctica.

El principio eudemonista de la ética tradicional -en los casos paradigmáticos tanto de la ética epicúrea como de la ética estoica, y por razones distintas pero convergentes- habría convertido la inclinación individual (a la consecución de la satisfacción sensual o de la felicidad) en clave de la orientación ética y elevado así la máxima subjetiva a regla universal. Se habría generado de este modo una ambigüedad relativa al concepto del sumo bien que impediría su determinación cabal; se trata del problema que movió a Kant a perseguir la fundamentación de la ética por medio de una deducción trascendental. ${ }^{18}$

En la raíz de dicha ambigüedad hallamos - de nuevo- una confusión entre principios subjetivos y objetivos. El regiomontano la incluye explícitamente entre los casos de lo que denomina "vicio de subrepción" (Fehler des Erschleichens, vitium subreptionis). ${ }^{19}$ Esta expresión conecta de forma muy significativa el análisis moral con la dilucidación del espejismo trascendental llevada a cabo en el apartado sobre los paralogismos de la razón pura teórica en la primera Crítica.$^{20}$ Todo ello nos legitima para reconocer en la heteronomía moral el correlato de la tercera modulación del concepto kantiano de prejuicio. Se desvela, de este modo, un poderoso hilo conductor que refuerza la unidad de sentido de las tres Críticas.

\section{Las causas del prejuicio y sus tipos}

\subsection{Causa universal: la inmadurez del intelecto provocada por la pereza}

Que en el pensamiento kantiano la inmadurez del intelecto tiene que ver con el prejuicio resulta patente. En el contexto de las consideraciones sobre el gusto que forman parte de la teoría del juicio estético, en la primera sección de la Crítica del juicio, el filósofo hace referencia a las tres máximas del entendimiento humano común:

Son las siguientes: 1. Pensar por sí mismo; 2. Pensar en el lugar del otro; 3. Pensar siempre en coherencia consigo mismo. La primera es la máxima del modo de pensar libre de prejuicios; la segunda, del ampliado; la tercera, del consecuente. La primera es la máxima de una razón que no es nunca pasiva. La tendencia a lo contrario y, con ello, a la heteronomía de la razón se denomina prejuicio; y el mayor entre todos consiste en representarse a la Naturaleza como no sometida a las reglas que el

\footnotetext{
${ }^{18}$ Cfr. Kritik der praktischen Vernunft (1788), Ak V, 110-113.

${ }^{19}$ Ibid., Ak V, 116.

${ }^{20}$ Cfr. B 349/A 293ss.
} 
entendimiento, por su propia ley esencial, le pone como fundamento: a saber, [se trata de] la superstición. La liberación de la superstición se denomina ilustración [Aufklärung]: ya que, aunque esta denominación corresponde también a la liberación de los prejuicios en general, [la superstición] merece ser llamada prejuicio por excelencia (in sensu eminenti), en cuanto que la ceguera a la que conduce, y a la que prácticamente obliga, da a conocer la necesidad de ser guiados por otros $\mathrm{y}$, de este modo, [promueve] el estado de una razón pasiva. ${ }^{21}$

Así pues, el prejuicio se halla emparentado con la culpable minoría de edad del sujeto. En la salida de dicho estado reconocemos el aliento básico de la Ilustración, tal y como queda patente en Respuesta a la pregunta: ¿Qué es Ilustración? En este ensayo, Kant responde a la pregunta que da título al texto con frases lapidarias que sus herederos hemos enarbolado como bandera: se trata de la salida de una minoría de edad no psicofísica sino culpable, puesto que no se debe a una falta de inteligencia sino a la ausencia del coraje preciso para emplearla. ${ }^{22}$

La principal causa de tal inmadurez reside en la pereza. Kant asimila este concepto a la noción de una razón pasiva, frente al uso espontáneo propio de la autonomía racional. Una razón pasiva no busca en sí misma la fuente de sus tomas de postura, sino que se abandona a principios que vienen de fuera y que no quedan tamizados por su propia crítica; no es autónoma y legisladora, sino heterónoma y esclava. En la pereza de una razón que abdica de sus responsabilidades reside la causa última del problema: «El prejuicio es el principium de un uso pasivo de la razón». La datación de este fragmento resulta aquí relevante, puesto que atestigua la radicación de la doctrina del prejuicio en la fase redaccional en la que se gestó el viraje crítico. ${ }^{23}$

\subsection{Causas particulares y tipos}

La investigación etiológica particular sobre el prejuicio se ha de desarrollar en el ámbito de la psicología empírica y resulta, por tanto, análoga a la cartografía en su relación con la geometría: válida, pues, en relación con sujetos psicofísicamente configurados de este o de aquel modo. Existirá, pues, una teoría detallada del prejuicio sólo en cuanto investigación relativa a cierta cultura, sociedad, colectivo o individuo. Además, el prejuicio puede convertirse en un hábito y, de este modo, en un defecto del

\footnotetext{
${ }^{21}$ Kritik der Urteilskraft (1790), Ak V 294-295.

${ }^{22}$ Cfr. Beantwortung der Frage: Was ist Aufklärung? (1784), Ak VIII 35ss.

${ }^{23}$ Reflexion zur Logik n. 2526, anotación al margen del ejemplar kantiano del Auszug aus der Vernunftlehre de G. F. Meier (1752). Dado que Erich Adickes sitúa la redacción de esta reflexión en la fase $\nu, \rho, \kappa$ o $\eta$, la datación oscila, por orden de probabilidad, entre los años 1771, $1773-75,1769$ y $1764-68$, respectivamente.
} 
carácter que se hallaría incluso entre personas eruditas. La casuística empírica resulta, pues, inabarcable. De hecho, Kant aborda sólo las causas del prejuicio atendiendo a su estructura lógica y sus principales tipos. Desde este punto de vista, la fuente a la que nos remitiremos ahora son las lecciones de lógica publicadas en 1800 .

El regiomontano distingue tres grandes fuentes de prejuicios, emparentadas entre sí: la imitación (Nachahmung), la costumbre (Gewohnheit) y la inclinación (Neigung). ${ }^{24}$ En los tres casos se trata de fenómenos provocados, en el fondo, por la acedia. Es una razón perezosa la que en lugar de buscar en sí misma los fundamentos de su acción se confía acríticamente al ejemplo del otro, se aposenta en los hábitos ya establecidos o sigue ciegamente sus propias inclinaciones.

De estas tres fuentes nacen dos tipos básicos de prejuicio. Cuando la voluntad se orienta hacia la imitación, da lugar a los prejuicios basados en la apariencia (Vorurtheile des Ansehens). La voluntad orientada hacia la imitación sobre la base de apariencias puede dejarse arrastrar por la admiración hacia una persona, cuyo criterio queda erigido en principio; por la asimilación con la masa, de tal manera que el individuo actúa como lo hacen los demás; o bien por la fascinación hacia un cierto período histórico, cuando se deja llevar por las tendencias propias de la época admirada. Por su parte, la inclinación (tercera de las fuentes citadas) puede dar lugar a prejuicios basados en el amor a sí mismo o egoísmo lógico (Vorurtheile aus Eigenliebe oder logischem Egoismus). Este tipo de prejuicio se da cuando se considera que la coincidencia de los juicios ajenos con los propios constituye el criterio básico de verdad. En cierto sentido se trata del fenómeno opuesto al anterior: mientras el prejuicio basado en las apariencias traslada el criterio fuera de sí (por admiración hacia una persona, imitación de la masa o fascinación por una época), el prejuicio basado en el amor de sí tiene su centro de gravedad en las propias tendencias y en su sobrevaloración. Finalmente, la costumbre (segunda fuente) puede reforzar los prejuicios que brotan de la imitación y de las propias inclinaciones. Cuando la imitación se convierte en costumbre -a menudo, favorecida por inclinaciones personales- el prejuicio resulta muy difícil de sanar:

Tales personas sólo pueden convertirse en copias de otros; si todos fuesen de esa índole, el mundo permanecería eternamente en el mismo lugar. Por ello, es sumamente necesario e importante no incitar a la juventud -como acostumbra a suceder-a la mera imitación. ${ }^{25}$

El regiomontano llega a señalar incluso algunos instrumentos pretendidamente pedagógicos que favorecerían el prejuicio: entre ellos, el aprendizaje basado en fórmulas, proverbios o sentencias.

${ }^{24}$ Sobre el plan general del tratamiento del prejuicio en la Logik, cfr. Ak IX 75-81.

${ }^{25}$ Logik (1800), Ak IX 76. 
Hay que notar que la doctrina kantiana sobre los tipos de prejuicio y sus causas refleja la enumeración que lleva a cabo Georg Friedrich Meier en su Extracto de la doctrina de la razón (Auszug aus der Vernunftlehre, Halle, 1752). Se trata de un manual divulgativo, versión reducida de su Vernunftlehre, que Kant empleó para la docencia en sus clases de lógica. En dicho manual encontramos dos elencos de prejuicios. El primero de ellos tiene que ver con el prejuicio básico de la confianza excesiva (Vorurtheil des gar zu grossen Zutrauens), e incluye los siguientes casos:

(1) El prejuicio de la de todo punto excesiva apariencia (praeiudicium auctoritatis), cuando aceptamos o rechazamos algo porque una persona, a la que admiramos hasta el punto de considerarla digna de imitación, lo acepta o lo rechaza. (2) El egoísmo lógico (egoismus logicus), cuando alguien tiene algo por lógicamente perfecto porque él mismo es su artífice. (3) El prejuicio de la Antigüedad (praeiudicium antiquitatis), cuando tenemos algo por verdadero porque se trata de una opinión antigua. (4) El prejuicio de la novedad (praeiudicium novitatis), cuando tenemos algo por verdadero porque se trata de una opinión nueva. (5) El prejuicio de la doctrina aceptada (praeiudicium systematis), cuando alguien acepta algo simplemente porque se adecua a nuestro conocimiento, y lo rechaza porque lo contradice. (6) El prejuicio de la confianza perezosa (praeiudicium pigritiae), cuando se confía en avanzar en el conocimiento erudito por medio de un esfuerzo reducido, tanto como si se aplicase un gran esfuerzo. (7) El prejuicio de la banalidad (praeiudicium corticis), cuando se cree poder avanzar igualmente con un conocimiento superficial que por medio de uno profundo. ${ }^{26}$

La segunda serie tiene que ver con los prejuicios de la excesiva desconfianza:

(1) El prejuicio de la Antigüedad (praeiudicium antiquitatis), cuando se rechaza algo porque es antiguo. (2) El prejuicio de la novedad (praeiudicium novitatis), cuando se rechaza algo porque es nuevo. (3) El prejuicio de los pueblos (nazarethismus), cuando se rechaza algo porque proviene de un determinado pueblo. (4) El prejuicio de la desconfianza remitida hacia sí mismo (praeiudicium nimiae diffidentiae in se ipsum positae), cuando uno confía demasiado poco en sí mismo, etc. ${ }^{27}$

El parentesco conceptual, así como la correspondencia literal en algunas expresiones, me lleva a afirmar que el Extracto de la doctrina de la razón de Meier constituye una más que posible inspiración inmediata de Kant en la construcción de su tipología de prejuicios. Ahora bien: respecto del tratamiento de la cuestión llevado a cabo por Meier la elaboración kantiana presenta dos grandes diferencias. Una de ellas es de índole formal: Kant sistematiza los tipos de prejuicio haciéndolos depender de tres grandes fuentes que subyacen a los casos concretos (a saber: imitación, inclinación y

\footnotetext{
${ }^{26}$ Meier, G. F., Auszug aus der Vernunftlehre (1752), incluido en Ak XVI, 414-416.

${ }^{27}$ Id., 416-417.
} 
costumbre) y apuntando a la pereza intelectual como causa última de la inmadurez reflejada en los prejuicios concretos. En cambio, Meier hace referencia a la pereza en el contexto de un caso particular de prejuicio (citado en sexto lugar y estrechamente emparentado con el séptimo tipo); los casos primero, tercero y cuarto de la primera tabla, así como los tres primeros de la segunda, quedan unificados por Kant como prejuicios basados en apariencias, mientras que el segundo y el quinto, así como el cuarto de la segunda tabla, quedan integrados como casos particulares del prejuicio arraigado en el amor a sí mismo.

La segunda diferencia atañe al sistema conceptual. El de Königsberg relaciona la doctrina del prejuicio con la confusión entre los fundamentos objetivos y subjetivos del conocimiento, permitida por una razón indolente; de este modo, la conecta con el núcleo de su epistemología y con la crítica subyacente a su refundación de la metafísica y de la moral. Esta ubicación sistemática trae consigo un matiz diferente respecto del tratamiento del prejuicio en la obra de Meier. Mientras que, según Meier, un prejuicio no tiene por qué conducir necesariamente a un juicio erróneo (puesto que atañe a los fundamentos subjetivos de nuestra adhesión y no al resultado veritativo) ${ }^{28}$, Kant tiende a negar esta tesis ${ }^{29} \mathrm{y}$ a poner el acento en la necesidad de eliminar todo prejuicio, dada la intrínseca maldad de éste ${ }^{30}$.

La razón de tal diferencia reside, a mi modo de ver, en el punto de vista desde el que cada autor se aproxima al tema: Meier, desde una sistematicidad puramente lógica; Kant, desde la perspectiva de las condiciones teórico-prácticas de la racionalidad objetiva, en la que la crítica de la metafísica tradicional (originada ésta, a su modo de ver, por un prejuicio) y la necesidad de promover la autonomía racional (frenada también por un prejuicio) le mueven a rechazar frontalmente un concepto que considera contrario al motor último de su pensamiento. Éste es también el motivo de que la posible vertiente positiva del prejuicio - por ejemplo, como freno prudencial a la hora de aceptar teorías novedosas hasta que no se disponga de garantías suficientes-ocupe poco espacio en la reflexión de Kant, y de que lo haga en estadios tempranos de su desarrollo. ${ }^{31}$

${ }^{28}$ Id., 402.

${ }^{29}$ Cfr. Reflexion zur Logik n. 2544 (fase $\theta$, v- $\chi$, entre 1780-83, 1776-1778 ó 1778-89). Esta reflexión contradice aparentemente lo anotado algunos años antes en el mismo ejemplar de Meier, cfr. Reflexion zur Logik n. 2562 (fase $\beta 1,1752-56$ ), lo cual testimonia una evolución interna a la que me referiré en el siguiente párrafo.

${ }^{30}$ Cfr., por ejemplo, Logik (1800), Ak IX 81.

${ }^{31}$ Entre los escasos ejemplos se encuentra la Reflexion zur Logik n. 2516 (fase $\beta 1$ ), anotación al margen del ejemplar kantiano del Auszug aus der Vernunftlehre de Meiner; según la datación de Adickes, la anotación se produjo entre los años 1752 y 1755. Cfr. también la Reflexion zur Logik n. 2519 (fase $\gamma$ o $\delta$, entre 1760-64 ó 1762-63), en la que la noción de prejuicio se aproxi- 
En este sentido, el regiomontano parece remitirse a una tradición que encontraría su referente más próximo no ya en Meier sino en la obra del filósofo, jurista y divulgador Christian Thomasius (1655-1728) y en la prosecución de ésta en la escuela wolffiana. Nos interesan aquí, en particular, los textos que caracterizan -junto con la edición de la revista Monatsgespräche-el viraje de Thomasius desde el ámbito del Derecho al de la Filosofía.

Me refiero a dos tratados complementarios: la Introducción a la doctrina de la razón (Einleitung zu der Vernunftlehre) y la Ejercitación de la doctrina de la razón (Ausübung der Vernunftlehere), ambos publicados en Halle en 1691. En ellos pone de manifiesto, en un modo eminentemente práctico, la inspiración ilustrada: su objetivo es favorecer - no ya sólo entre los eruditos, sino de forma accesible a todos- el uso de una razón sana, rectamente guiada, que promueva los fines de la Humanidad. En dicha tarea el requisito fundamental consiste en la eliminación de los prejuicios; de ahí que Thomasius manifieste su deseo de buscar

el nacimiento (Hauptquelle) de todos los prejuicios y, a partir de ahí, los distintos arroyuelos (Bächlein) que de él brotan y que obstaculizan nuestro examen de la verdad en todas las disciplinas y ciencias. ${ }^{32}$

En los textos se evidencia un innegable parentesco intelectual con la distinción kantiana entre filosofía en sentido escolástico (Schulbegriff der Philosophie) y filosofía en sentido cosmopolita (Weltbegriff der Philosophie). ${ }^{33}$ Dicha distinción se halla anticipada en la obra de Thomasius por la diferencia entre Gelehrheit (conocimiento erudito) y Gelahrheit (discernimiento de la verdad abierto a todos con fines prácticos) ${ }^{34}$. Hay que notar, con todo, una divergencia relevante. Se trata de una distancia observable en la teoría sobre el despliegue de las condiciones volitivas de la acción. Thomasius le dedica dos tratados paralelos a los consagrados a la doctrina de la razón: la Introducción a la doctrina de las costumbres (Einleitung zu der

ma a la de juicio provisional en el sentido de hipótesis de trabajo. En aparente contradicción con esto último se halla la Reflexion zur Logik n. 2523 (fase $\eta^{2}, \kappa^{3}$ o $\mu$, entre 1764 y 1771). Todo ello testimonia la indefinición que el matiz positivo del concepto de prejuicio reviste en esa fase de desarrollo del pensamiento kantiano.

${ }^{32}$ Thomasius, Ch., Einleitung zu der Vernunftlehre, introducción, p. 26 de la edición de 1699 (Christoph Salfeld, Halle).

${ }^{33}$ Cfr. B 866- 867/A 838-839.

${ }^{34}$ Cfr. ibid., p. 1-2 del primer capítulo ("Von der Gelahrheit insgemein"); v. Einleitung zu der Sittenlehre (1696), primer capítulo ("Von der Gelahrheit das Gute und Böse zu erkennen überhaupt”), p. 5. El término alemán 'Gelehrheit' se corresponde con el actual 'Gelehrsamkeit'; en cambio, 'Gelahrheit' se halla hoy en desuso y no posee un equivalente léxicamente emparentado. 
Sittenlehre) y su correspondiente Ejercitación (Ausübung der Sittenlehre), ambos de 1696; en ellos afronta la determinación de la voluntad por inclinaciones, deseos y pasiones (desde el hedonismo a la ambición y la avaricia) que tuercen la intención moral. Para Thomasius, dichas pasiones sólo pueden ser reconducidas por medio de la apelación expresa a la gracia divina. Se echa de ver en este punto una filiación respecto de la perspectiva pietista que distancia su postura respecto del análisis kantiano de la acción.

Con todo, y en palabras de Salvatore Stefanelli, «la kantiana "liberación de los prejuicios" arranca en la Ilustración alemana con Christian Thomasius, según el cual la actividad cognitiva requiere aufräumen [ordenar] allí donde se debe poner orden y estructurar las propias opiniones y, por lo tanto, se debe establecer la validez de éstas. Para alcanzar lo que Kant denominará Selbstdenken [pensamiento autónomo], Thomasius exhorta a incoar una actividad de autocrítica contra los praejudicia praecipitationis [prejuicios causados por la precipitación] y los praejudicia auctoritatis [prejuicios asociados a la autoridad], aconsejando el uso de la lógica como fármaco privilegiado contra estos vicios del intelecto»». ${ }^{35}$

Desde esa perspectiva, el prejuicio era contemplado exclusivamente como fuente de errores cognitivos y como enemigo frontal de la Ilustración. Paola Rumore ha hecho notar cómo dicha noción peyorativa halla uno de sus defensores más influyentes en René Descartes, a través de cuyo planteamiento «el término 'prejuicio' es entregado a la Modernidad grosso modo con el significado de 'error' o bien de 'opinión acogida de manera precipitada, fuente de ulteriores juicios falaces'»». ${ }^{36}$ Tal comprensión peyorativa del prejuicio se halla igualmente en Spinoza, quien dedica el Apéndice de la primera parte de su Ética a identificar y remover prejuicios que «hubieran impedido y pueden impedir a los hombres asir el encadenamiento de las cosas de la manera en que lo he explicado»; por lo cual, afirma, «he creído que valía la pena someterlos aquí al examen de la razón». ${ }^{37}$

\footnotetext{
${ }^{35}$ Stefanelli, S., «Recensione sui Contributi alla dottrina dei pregiudizi del genere umano» [fuente electrónica].

${ }^{36}$ Rumore, P., introducción a Meier, G. F., Contributi alla dottrina dei pregiudizi del genere umano [versión italiana de Beyträge zu der Lehre von den Vorurtheilen des menschlichen Geschlechts], p. VII.

${ }^{37}$ Spinoza, B., Ethica, ordine geometrico demostrata, traducción de Oscar Cohan (realizada a partir del texto latino publicado en las obras completas editadas por Van Vloten y Land, La Haya, 1914): Ética demostrada según el orden geométrico, Gredos, Madrid, 2011, p. 38. Hay que notar, sin embargo, que la dilucidación del contenido de los prejuicios lleva a Spinoza por derroteros muy diferentes de los kantianos, relacionados con su diferente comprensión del papel de la teleología en la explicación de los procesos que tienen lugar en el mundo.
} 


\section{Reflexiones conclusivas: sobre la eliminación de los prejuicios}

Hemos visto cómo el prejuicio muestra en Kant tres grandes acepciones, todas ellas peyorativas: la epistemológica general, la epistemológica particular y la práctica. El prejuicio implica el abandono a una razón perezosa. Desde la primera perspectiva, para eliminar los prejuicios resulta necesario despertar la razón crítica; ésta ha de evitar tomar por objetivos los que son sólo fundamentos subjetivos del juicio. Por esto, la eliminación del prejuicio constituye un relevante hilo conductor de la Crítica de la razón pura. Desde la segunda perspectiva (científico-natural), eliminar los prejuicios equivale a abrirse a la teleología interna de la Naturaleza como estrategia heurística. Kant nos persuade de la racionalidad de lo real y de que vale la pena emprender la indagación científica con la esperanza de que ésta nos devuelva una imagen inteligible, unitaria, valiosa, aprovechable. Por esto, la eliminación del prejuicio constituye un relevante hilo conductor de la Crítica del juicio. La tercera perspectiva (práctica) nos ha permitido constatar la comparecencia de una subrepción análoga a la que se produce en la razón teórica y que lleva a considerar como si fueran objetivos los que son móviles meramente subjetivos (y heterónomos) de la razón práctica. Así pues, la eliminación del prejuicio vertebra el proyecto de una moralidad autónoma en el camino desde la Fundamentación de la metafísica de las costumbres a la Crítica de la razón práctica.

Lo opuesto de la apertura activa a la realidad consiste en la cerrazón perezosa en la propia visión del mundo. Querría concluir concretando este asunto, a modo de ejemplo, en algunos fenómenos pertinentes desde el punto de vista cultural. Tal y como afirma Diéguez Lucena, la filosofía «no es un pensamiento ensimismado, ocupado perennemente en los viejos problemas legados por su propia tradición, sino que ha sido siempre, y lo es más explícitamente hoy, una tarea de reflexión sobre los problemas que preocupan a los seres humanos en cada situación histórica» ${ }^{38}$ Kant deja a cada época la tarea empírica de identificar qué actitudes abonan los prejuicios. Podemos ejercitarnos, pues, examinando alguno de los rasgos de la cartografía actual del prejuicio con la ayuda de la geometría conceptual proporcionada por Kant.

Las instancias favorecedoras de prejuicios son múltiples. La actitud básica que les da pábulo - la acedia- se ve alentada en nuestros días por una poliédrica desconfianza en la razón que halla su origen en la crisis de la cultura moderna. El cosmos racional, luminoso y prometedor de la Modernidad reveló su debilidad interna en el proceso social y político que dio lugar a la Gran guerra y a los regímenes dictatoriales y totalitarios del siglo XX. La crisis del modelo cultural moderno se ha proyectado sobre

${ }^{38}$ Diéguez Lucena, A., La evolución del conocimiento. De la mente animal a la mente humana, Biblioteca Nueva, Madrid, 2011, p. 15. Cfr. B 867 / A 839. 
todos los ámbitos de la vida: el ideal racional del progresivo e imparable perfeccionamiento de la Humanidad ha dado paso así a una mentalidad a menudo epistemológicamente escéptica y éticamente relativista. La crisis postmoderna suele implicar una cierta cerrazón en lo individual, en lo subjetivo, en lo provinciano, frente a la ilimitada confianza en la razón propia de la Modernidad. La tensión entre dicha tendencia postmoderna y potentes instancias globalizadoras (entre ellas, internet) está dando lugar a complejos fenómenos sociológicos.

Es en este contexto en el que podemos entender, al menos en parte, la modulación actual del concepto de prejuicio. En nuestros días, la razón perezosa está siendo abonada, entre otras instancias, desde poderosos medios de comunicación que, lejos de abrirnos al mundo, nos recluyen en una imagen depauperada y provinciana. Me refiero, por ejemplo, a numerosos mass media audiovisuales que han apostado por contenidos profundamente pueriles. Lejos de ayudarnos a desentrañar el mundo, nos persuaden de que para vivir en él basta con poca formación y poco esfuerzo (faule Vernunft); nos alienan de nuestra vida real, para ofrecernos modelos que sólo poseen consistencia de cara a la galería y que constituyen el objeto de una adhesión acrítica (Vorurteile des Ansehens); nos convencen a la vez de que en nuestra perezosa imitación de tales modelos estamos siendo, por fin, nosotros mismos (Vorurteile aus Eigenliebe oder logischem Egoismus).

El prejuicio, enseña Kant, constituye una fuente de errores que ha de ser erradicada. En palabras del regiomontano, «favorecer los prejuicios de alguien equivale a engañarle con buena voluntad». ${ }^{39}$ Frente a una razón perezosa, causa original del prejuicio, Kant propugna la necesidad de cultivar una disposición intelectual abierta a descubrir la racionalidad de lo real. Nos deja el mensaje de que vivimos en un mundo en el que podemos encontrar significado y -lo que es aún más importante- poner sentido a través de nuestra acción transformadora.

\section{Bibliografía}

Caygill, H. A Kant Dictionary. Blackwell, Oxford, 1995.

Coromines, J. Breve diccionario etimológico de la lengua castellana (1961). Gredos, Madrid, 2008.

Deligiorgi, K. Kant and the Culture of Enlightenment. Suny Press, Nueva York, 2005.

EISLER, R. Kant-Lexikon (1930). Olms, Hildesheim, $1989^{4}$.

Kant, I. Gesammelte Schriften. Königliche Preußische Akademie der Wissenschaften / Georg Reimer / Walter de Gruyter / Vereinigung Wissenschaftlicher Verlager / Akademie der Wissenschaften zu Göttingen / Akademie der Wissenschaften der DDR, Berlín / Leipzig, 1907-.

${ }^{39} \operatorname{Logik}(1800)$, Ak IX 81. 
MeIER, G. F. Auszug aus der Vernunftlehre (1752). En Kants gesammelte Schriften, vol. XVI.

- Beyträge zu der Lehre von den Vorurtheilen des menschlichen Geschlechts. Edición de N. Hinske, H. Delfosse y P. Rumore, Frommann-Holzboog, Stuttgart, 2005.

Rumore, P. Introducción a MeINER, G. F. Beyträge zu der Lehre von den Vorurtheilen des menschlichen Geschlechts / Contributi alla dottrina dei pregiudizi del genere umano. ETS, Pisa, 2005.

Sassen, B. «18th Century German Philosophy Prior to Kant», en Zalta, E. N. (ed.). The Stanford Encyclopedia of Philosophy (edición: otoño de 2011). $<$ http://plato.stanford.edu/archives/fall2011/entries/18thGerman-preKant/> [consulta: 04.07.2013].

SPINOZA, B. Ethica, ordine geometrico demostrata (redactada entre 1663 y 1675 y publicada póstumamente), en Opera, edición crítica de C. Gebhardt, C. Winter, Heidelberg, 1972.

Stefanelli, S. «Recensione sui Contributi alla dottrina dei pregiudizi del genere umano». Recensioni filosofiche. $<$ http://www.recensionifilosofiche.it $>$ [consulta: 19.10.2010].

Teruel, P. J.: "Die äußere Schaale der Natur. Eine Fußnote zum Versuch über die Krankheiten des Kopfes (1764)”, Kant-Studien 104, 1 (2013) 23-43.

_ "Das „Ich denke“ als „der alleinige Text der rationalen Psychologie“. Zur Destruktion der Seelenmetaphysik und zur Grundlegung der Postulatenlehre in der Kritik der reinen Vernunft", en Fischer, N. (ed.): Kants Grundlegung einer kritischen Metaphysik. Einführung in die >Kritik der reinen Vernunft<, Hamburgo, Felix Meiner, 2010, pp. 215-241.

Thomasius, CH. Einleitung zu der Vernunftlehre, Christoph Salfeld, Halle, 1691. Reproducción fotomecánica en Ausgewählte Werke, vol. 8, Georg Olms, Hildesheim, 1998.

— Einleitung zu der Sittenlehre, Christoph Salfeld, Salle, 1696. Reproducción fotomecánica en Ausgewählte Werke, vol. 10, Georg Olms, Hildesheim, 1995.

Pedro Jesús Teruel

Universidad de Valencia

Departamento de Filosofía

pedro.teruel@uv.es 